Article

\title{
Assessing Socio-Economic Impacts of Agricultural Subsidies: A Case Study from Bhutan
}

\author{
Sonam Wangyel Wang ${ }^{1,2}$, Belay Manjur ${ }^{3}\left[\right.$, Jeong-Gyu Kim ${ }^{1}\left(\mathbb{D}\right.$ and Woo-Kyun Lee ${ }^{3, *}$ \\ 1 Ojeong Eco-Resilience Institute (OJERI), Division of Environmental Science and Ecological Engineering, \\ College of Life Sciences, Korea University, Seoul 02841, Korea; wangsonam@korea.ac.kr (S.W.W.); \\ lemonkim@korea.ac.kr (J.-G.K.) \\ 2 Bhutan Institute of Himalayan Studies, Wang Simu, P.O. Box 2049, Thimphu, Bhutan \\ 3 Division of Environmental Science and Ecological Engineering, College of Life Sciences, Korea University, \\ Seoul 02841, Korea; arsemabm@gmail.com \\ * Correspondence: leewk@korea.ac.kr
}

Received: 19 April 2019; Accepted: 5 June 2019; Published: 13 June 2019

check for updates

\begin{abstract}
As an agrarian nation, Bhutan's agricultural policies prioritize agricultural subsidies to boost agricultural production, rural incomes, improve food security, and reduce income poverty, especially among the rural poor. However, the effectiveness and efficiency of such policy interventions remains unknown. Based on semi-structured interviews with heads of households from six blocks representing two districts, expert consultation with agricultural policymakers and extension agents, we attempted to evaluate the socio-economic impacts of agricultural subsidy programs including co-payments. The study found that while over $90 \%$ of the households received at least one form of subsidy, except for agricultural machineries and piglets, the non-poor population has greater access to the subsidies compared to the poor. For instance, only $35 \%$ of the poor received seed and sapling subsidies compared to $52 \%$ seeds and 39\% sapling subsidies received by the non-poor population. Furthermore, none of the poor received Jersey cow or biogas subsidies due to their inability to co-pay. Additionally, the agriculture machinery subsidy was found to be counterproductive to the lower income groups (<US\$153.85) and beneficial to the higher income groups. However, $14.5 \%$ of the households who received a poultry subsidy experienced 3 times more income (at a mean income change of 634.31 US\$) compared to those who did not, indicating that this subsidy has larger potential to improve income for the poor. To efficiently achieve the objectives of increasing rural income and reducing poverty, we recommend agricultural subsidy programs and projects be provided as a package to poor small holders, where inputs are given based on existing capacity, availability of technical support, and market accessibility.
\end{abstract}

Keywords: agriculture; subsidy; Bhutan; farm machinery; co-payments; poverty

\section{Introduction}

Despite the overwhelming opposition to agricultural subsidies in the USA and EU by developing countries, Brazil, Russia, India, Indonesia, and China have adopted subsidies and are seeing an unprecedented increase [1,2]. For instance, by 2012, China's agricultural subsidies accounted for over US $\$ 160$ billion compared to US ( $\$ 19$ billion) and EU ( $\$ 67$ billion). Brazil spent $\$ 10$ billion on agricultural subsidies in the same year. In addition, India's subsidy for wheat and rice increased by $72 \%$ and $75 \%$ respectively, exceeding those in the USA. On average, the US alone spent a staggering US $\$ 17$ billion annually (1998-2004), which is larger than what they spent on needy families (averaged 13.6 billion) and postsecondary students (16.1 billion) [3]. The goal of subsidy programs as articulated by many developing country governments is to improve farmers' incomes and national food security 
by increasing food production [4]. Concerns are often expressed about whether subsidy programs meet national policy objectives more efficiently than other public investments in agriculture [5].

These increasing allocations of funds indicate that agricultural subsidies form an important component of the agricultural policy of the world's fastest growing economies, confirming its legitimacy $[2,6]$. The main argument is that without the subsidies, agricultural farmers will not be able to compete with imported products [7] and associated economic, environmental, and social benefits [6]. However, agricultural subsidies have been associated with failures and successes at achieving their original goals, be that poverty alleviation, food security, and/or international trade [8-10]. Subsidy failures have been often triggered by high costs and approaches that were universal in coverage, where benefits spread beyond the target groups [11-13]. Experts also caution that excessive and broad-based subsidies can prove to be negative, leading to inefficiencies $[11,14]$. For instance, broad based subsidies on fertilizers, pesticides, and seeds can not only lead to resale opportunities but can also cause overuse, resulting in soil degradation, ground water depletion, and pollution of water systems $[15,16]$. On the other hand, experts agree that subsidies-if designed well by targeting specific groups of beneficiaries-can support innovation and help build more resilient communities by increasing productivity, generating incomes from sale of surpluses, and alleviating poverty $[11,12,15,17,18]$. These findings demand that given the competing resource needs by different sectors, agricultural subsidies must be driven by need and should lead to increases in productivity, efficiency, and regional/global competitiveness. Many governments around the world are today re-thinking agricultural subsidies and rebranding them as "smart subsidies" which rely on improved institutional and implementation capacities that encourage private sector development and target beneficiaries more accurately $[8,9,11]$.

Bhutan, with $69 \%$ of its population engaged in agriculture that contributes $15.18 \%$ of its GDP [19], has prioritized agricultural policies and programs that target poverty reduction through multiple approaches including input subsidies. Government subsidies are granted as a tool in agriculture development and transfer of technology particularly for the remote areas of the country, whereby input subsidies have been a means of accelerating food production and generating farm incomes. Despite Bhutan's significant attempts, over half a decade after its first planned development programs went into action, the country is still grappling with poverty and food insecurity. Recent figures from Bhutan's National Statistical Bureau [20] report around one-third of the country's people, mostly belonging to rural areas, continue to live below the poverty line.

Bhutan's Ministry of Agriculture and Forests (MoAF), in charge of boosting agricultural development in collaboration with other line agencies including the Central Planning Authority, the Gross National Happiness Commission (GNHC) has been strengthening its efforts to make its traditional agricultural subsidy program 'smart' by shifting from a broad based approach to targeted poverty alleviation. Accordingly, MoAF, came up with Renewable Natural Resource (RNR) Subsidy Policy in 2010 [21], which aims to promote farmer wellbeing and enhance sustainable livelihoods, strengthen backward and forward linkages in the supply chain, and provide policy support to generate additional employment and income. The policy also delineates the need to incorporate a monitoring and evaluation system as part of the subsidy policy in order to provide appropriate information at the right level of detail corresponding to intended targets.

To put this policy into practice, GNHC and MoAF have spearheaded targeted poverty alleviation programs which involved subsidized agricultural inputs. Two such signature programs included: (1) Rural Economy Advancement Program (REAP—executed by the Gross National Happiness Commission); and (2) Rural Livelihoods Program (RLP-executed the by Ministry of Agriculture and Forests). The overall macro-strategy of these programs for poverty reduction includes promoting economic opportunities through broad-based growth and boosting critical sectors such as agriculture and rural industries/enterprises that are important for the poor. These programs focused on the reduction of extreme poverty and, as such, targeted the poorest villages and blocks in the country. These programs endeavored to take into consideration the special needs of the rural poor who have not benefited much from broad-based poverty reduction interventions and economic growth, and 
to address them specifically through targeted interventions that supplement, in a synergistic way, mainstream development efforts. The implementation was also anchored at the local level, benefiting from the technical support of the various sectors, while the GNHC takes responsibility at the central level for coordination of the implementation of the interventions and program evaluation.

The RLP was executed by the Ministry of Agriculture and Forest (MoAF) to reverse the dire situation of farmers and eventually alleviate poverty in some of the highest poverty incidence blocks located in the Zhemgang and Sarpang districts. The project's goal was to contribute towards improvement of livelihood of rural poor in Bhutan through pro-poor, holistic, community-driven, and participatory approaches. Consequently, different agricultural subsidy interventions have been implemented over the 4 years of the project duration (2012-2016) to enhance income to alleviate rural poverty and improve resilience at household levels. The Draft Renewable Natural Resources Subsidy Policy 2010, was used to guide subsidy interventions through this project. Global experiences also suggest that the success of such programs depends on a variety of factors, including rural access to markets and services to identify gaps and opportunities that depend on the availability and quality of infrastructure, and on the institutional environments $[8,11]$. In addition, the success of such interventions is dictated by the feasibility of interventions and equitable access to such interventions. Consequently, policy and program evaluations are necessary to identify best and worst practices to inform policy makers and the public on what interventions have been effective, which ones have failed to achieve the original objectives [22], and what changes can be attributed to the introduction of a particular intervention program or policy [23]. However, such programs are rarely evaluated against their original aims and objectives. While there is a growing number of studies focusing on assessing the socio-economic and environmental impacts of agricultural subsidies, fewer such studies have been undertaken in developing countries of Asia $[24,25]$ and, in particular, no such studies exist for Bhutan. Our study attempted to: (1) evaluate the socio-economic impacts of agricultural subsidy interventions; (2) assess the efficacy of the cost sharing interventions; and (3) suggest policy recommendations to further improve the policy and efficiency, effectiveness, and sustainability of the subsidy interventions.

\section{Methodology}

\subsection{Study Area}

This study was carried out in Bhutan involving consultations with policy makers and extension agents from the agricultural sectors and field survey in six blocks (Blocks: are sub-districts, and Bhutan has 205 blocks) from Zhemgang (three blocks) and Sarpang (three blocks) districts (Bhutan has 20 districts) (Figure 1).

The districts of Zhemgang and Sarpang are associated with the highest poverty rates $(56 \%$ and $27 \%$, respectively) hosting some of the poorest blocks in the country and are hence a priority target for poverty alleviation programs. The selected blocks for our study (Table 1) are the poorest within these two districts. As with most parts of Bhutan, rural livelihoods are characterized by near subsistence agriculture because of small land holdings, scattered settlements, long distances to road-points, and markets. Farmers grow rice on wetlands and cash crops such as oranges and cardamom on the dry lands. In addition, farmers also keep poultry, raise pigs, and engage in production of cane and bamboo products, especially in the Bjoka block. Although, Bhutan's National Statistical Bureau, reported that $99 \%$ of the total households in the two districts $(N=3533)$ own land, the percentage of arable land per household is very limited [20]. Therefore, most rural families are not food self-sufficient throughout the year and have to purchase food (mainly rice) during some months. Depending on the altitude (settlements are located from $200 \mathrm{~m}$ a.s.l. to $2500 \mathrm{~m}$ a.s.l.) and on the availability of water, which is influenced by rainfall that varies from $1500 \mathrm{~mm}$ in higher elevations to $4000 \mathrm{~mm}$ in lower elevations per year, different agricultural production systems prevail and offer accordingly different livelihood strategies. 


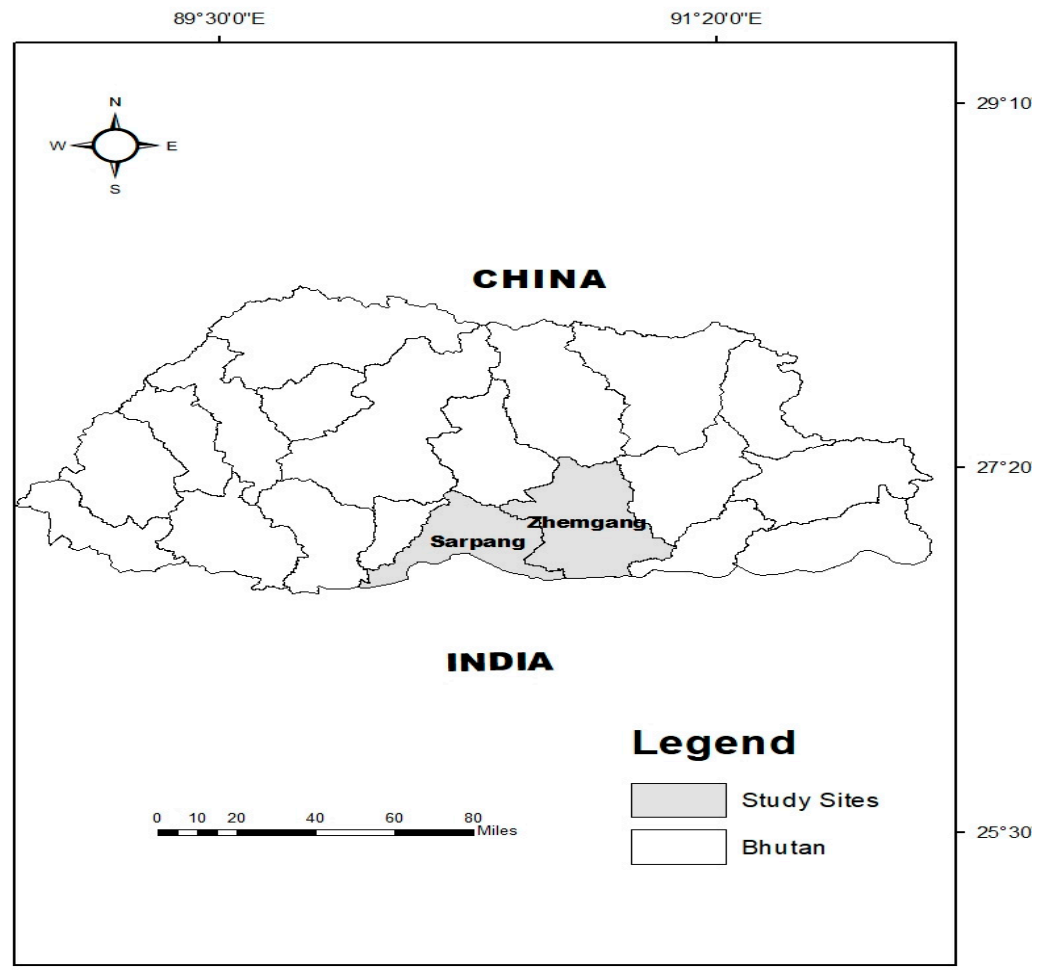

Figure 1. Map of study area in relation to Bhutan

Table 1. Characteristics of study blocks in the two districts

\begin{tabular}{ccccc}
\hline Districts & Blocks & HH (N) & * Poverty Rate (\%) & Population \\
\hline Zhemgang & Phangkhar & 330 & 64 & 2245 \\
& Bjoka & 155 & 60 & 871 \\
& Bardo & 373 & 61 & 4000 \\
& Total Zhemgang & 858 & & 7116 \\
Sarpang & Chhudzom & 397 & 39 & 4105 \\
& Jigme Choeling & 688 & 33 & 5229 \\
& Gakiling & 473 & 32 & 3486 \\
Total & Total Sarpang & 1558 & & 12,820 \\
& & $\mathbf{2 4 1 6}$ & & $\mathbf{1 9 , 9 3 6}$
\end{tabular}

\footnotetext{
* Bhutan government recognizes poverty as a multidimensional phenomenon. In the Poverty Analysis Report (2007) poverty is defined as: "the deprivation of the basics of life which, includes not just insufficient consumption (and income) but also lack of opportunities and assets, inadequate education, poor health and nutrition, lack of sanitation, insecurity and powerlessness." The National Statistics Bureau, Royal Government of Bhutan considers that the per-capita consumption expenditure offers a good representation of the wellbeing of households and of poverty. A minimum acceptable standard of that welfare indicator is used to separate the poor from the non-poor, and was calculated at Nu.688.96 (US\$1.25) per person per month as the extreme poverty line and Nu.1096.94 (US\$2.50) per person per month as the total poverty line.
}

Ecologically, the study area exhibits tropical to subtropical conditions, which changes to temperate ecosystems at higher mountains. The vast forest coverage (86\% in Zhemgang, $83 \%$ in Sarpang) is an additional important livelihood asset providing a variety of wood and non-wood forest products which supplement agricultural produce for subsistence as well as to earn cash incomes. Typical sources of income are the sale of dairy products (butter and cheese), horticulture products (in particular mandarins and cardamom), non-wood forest products (NWFP), seasonal daily labor on construction sites, porter services, and remittances from relatives in urban areas. Vehicle road access is also improving. 


\subsection{Methods}

As a welfare state, Bhutan's government has provided agricultural subsidies in the form of seeds, saplings, fertilizers, pesticides, agricultural machinery, livestock, etc., since the start of planned development in the 1950s. Subsidies are channeled from the Ministry of Agriculture to the beneficiaries through the local governments, which serve as distribution and verification points. Local governments inform the communities about the availability of subsidies through public meetings. All the farmers are, by default, eligible and can receive any such subsidies. However, they can also opt out if they decide to not receive any of the subsidies. Since the 1980s, a co-payment requirement has been introduced especially for expensive inputs such as agricultural machinery and livestock. However, this unintentionally disadvantaged the less well-to-do farmers as they were not able to meet the copayment amounts. In some instances, they availed loans to match the co-payment amount and became indebted to banks or rich neighbors. To streamline and to improve the efficiency and effectiveness of the subsidy program, the Ministry of Agriculture and Forests has recently formulated a subsidy policy. We used quantitative and qualitative information collected from an agriculture expert group and household interviews to evaluate the efficacy of this policy and project interventions.

\subsubsection{Respondent Survey}

To gather representative data, a survey was carried out with two groups of respondents: (i) an agriculture expert group, consisting of agriculture policy experts and local extension agents; and (ii) farm households. The surveys took place between January and February, 2017.

Expert surveys are proven to generate much more data about interviewees than the other tools and are excellent for collecting high quality information [26-28]. We carried out an agriculture expert group survey of 25 (10 females and 15 males) experts, randomly selected from a list of agricultural officers obtained from the Ministry of Agriculture and Forests. This sample consisted of agriculture policy experts from the ministry's head office and extension officers from the study blocks. The survey used a pre-tested semi-structured questionnaire with four sections. Section 1, collected personal details about the respondents including their position, gender, education level, and contact details. Section 2, explored their views on the draft subsidy policy (formulation process, participation, awareness, and experiences in implementing the draft policy). In Section 3, respondents were questioned about the efficacy of subsidy interventions, socio-economic impacts, challenges, and future plans. Finally, Section 4, asked the respondents to segregate policy interventions that are effective in alleviating rural poverty from those that are not effective and also integrate gender aspects and provide suggestions for improvement. Each survey took about 20-30 min.

Household surveys based on a semi-structured questionnaire are a standard method in social and natural sciences [29]. We interviewed 125 (61 females and 64 males) household heads selected through a two-step random sampling procedure. First, six of the poorest blocks were randomly selected from the two sample districts which were also the recipient of agricultural subsidies through the rural livelihood project (Table 1). In the second step, 125 sample households were randomly drawn from the list of registered households obtained from the block administration offices. This sample was representative of those who received and not received subsidies. A pre-tested semi-structured questionnaire was then used to interview the selected household heads for about 30-40 min each. Published scientific literature [30-32] suggests that household poverty and coping abilities are determined by factors linked to government policy interventions introduced to address the problem of poverty and resilience. Our household survey questionnaire was organized into five sections. The introductory section collected demographic information about the household including number of family member by gender, age, education level, land ownership, quality of housing, income, sources of income, etc. Sections 2-5 questioned the household heads on the types of subsidies received, changes in income post subsidy, affordability of subsidies, financing options, access to markets, and compared them with those who did not receive subsidies. We focused on subsidies such as agriculture machinery, high yielding varieties of crop, livestock farms, and self-help groups, and analyzed their relationship to poverty. All the factors 
were a priori expected to have a positive impact on the income and living conditions of households and therefore improve their resilience towards both climate and non-climate related risks.

\subsubsection{Empirical Approach to Analysis}

Data was encoded into SPSS (quantitative) and excel (qualitative) databases, cleaned, and analyzed. Statisticians recommend using logit or probit models when the dependent variable is dichotomous [33]. Many researchers prefer to use the logit model because of its comparative mathematical and interpretational simplicity [34]. Accordingly, our study used logit models to analyze the relationship between project interventions, income, and household poverty status. Poverty is defined in terms of the average monthly per capita income of US\$26.28 (Nu1708.4) [35].

Logit regression was used to first predict the probability that a household received a subsidy and then to examine the impact of subsidy inputs—such as agriculture machinery, seeds, sapling, livestock, etc.- on household income. In practice, beneficiary households received different combinations of subsidies including seeds, sapling, agricultural machinery, etc. In the multinomial logit model equation below, the dependent variable $\gamma$ was categorical, with one category for no subsidized input received, a second category indicating the household received different farm inputs.

$$
\gamma=\beta 0+\beta 1 \mathrm{~T}+\varphi \mathrm{H}+\alpha \mathrm{L}+\varepsilon
$$

Household-level factors $\mathrm{H}$ also included a set of binary variables for whether or not the household received information about new subsidies in the last year from agricultural extension officers, other farmers, or the media [18]. To assess whether there were locational differences $\mathrm{L}$ in administration of the subsidy program, variables were included in the equation for the distance $(\mathrm{km})$ to the nearest road, and market, and to indicate the household resided in the study area.

The subsidy program was intended to benefit the most vulnerable farm households in each community, identified by local government officials. Variables indicating the household's level of vulnerability were expected to influence subsidy receipts and were therefore included in the equation, gender, age, and educational attainment of the household head, the size of the household's agricultural landholding, the household's wealth position, and the number of household members. The wealth level variable was created using principal components analysis [36], based on components reflecting household ownership of physical assets (land, motorcycle, bicycle, radio, television, refrigerator, mobile phone, and livestock), access to utilities and infrastructure (electricity, main source of drinking water), and housing characteristics (type of wall, floor, and roofing material of the dwelling unit, type of toilet, number of rooms per person).

The household-level factors $\mathrm{H}$ hypothesized to influence variables for labor supply (number of adults and older children in the household), access to cash or credit to participate in the subsidy program (wealth level, non-labor income, and access to credit), access to information about new seeds from government agricultural extension officers, other farmers, or media.

The locational factors, $\mathrm{L}$, include a variable for distance $(\mathrm{km})$ to the nearest major road (primary and secondary network) to measure agricultural market access. Quantitative statistics were supplemented by qualitative information in the form of participants' narratives about their experiences.

\section{Results}

Overall, major subsidies handed over by the government included seeds, saplings, piglets, poultry, agricultural machinery, corrugated iron sheets (CGI), biogas, and Jersey cows (Figure 2). Generally, the study indicated that the non-poor availed a larger share of the subsidies on seeds, saplings, Jersey cow, biogas, and CGI, while more piglets and agricultural machines were availed by the poor. 


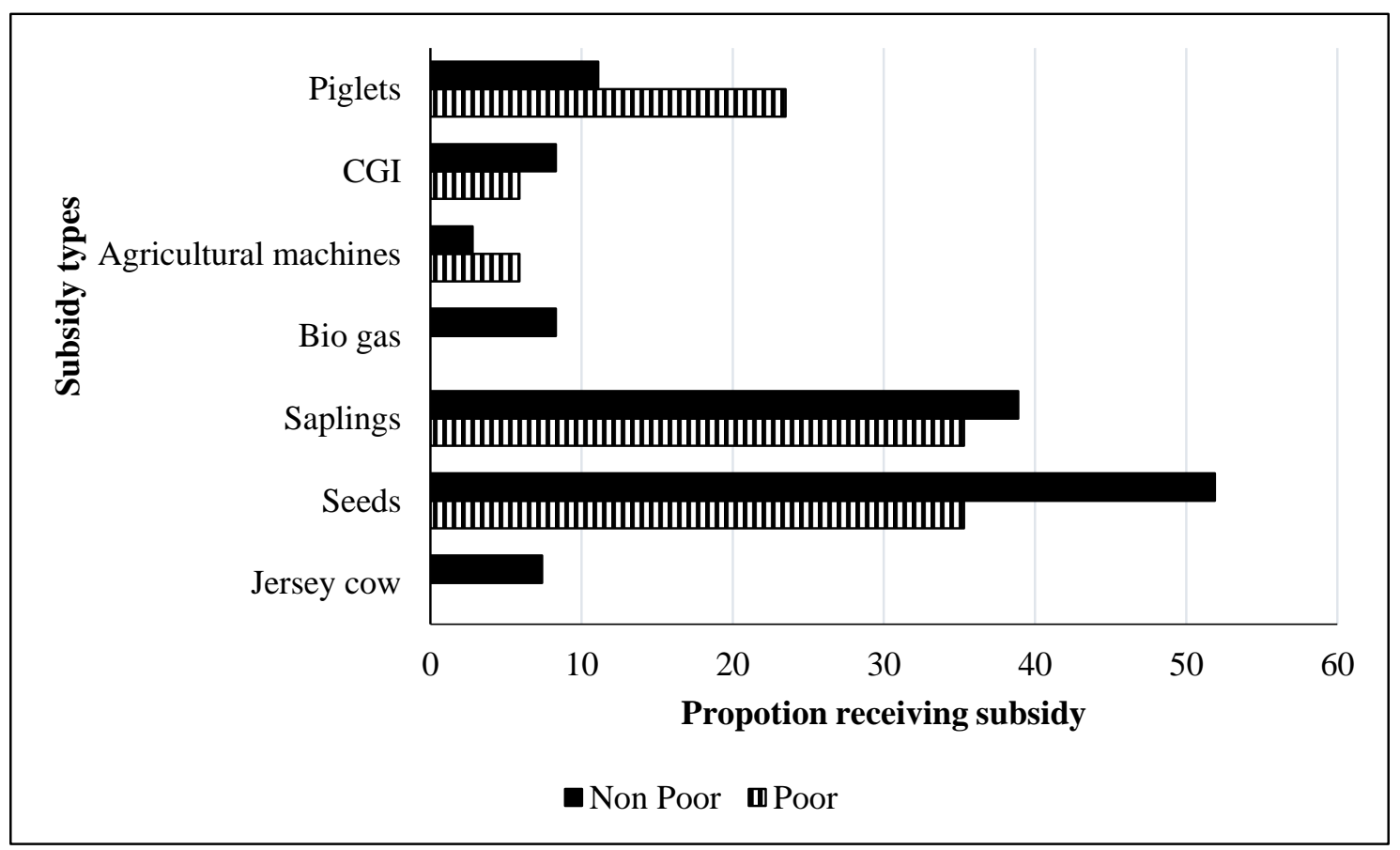

Figure 2. Percentage of households who received subsidies

\subsection{Livestock and Biogas Subsidy}

Evidence emerging from the data using OLS linear regression estimates suggests that only biogas $(p<0.05)$ had a statistically significant impact on income. Those who received a subsidy on biogas experienced about $27.8 \%$ increase in income. Unfortunately, none of the poor received subsidy on the Jersey cow and biogas (Table 2). Table 2 also shows that Jersey cows were availed by higher income groups who earned more than US\$384 $(>25,000)$.

Table 2. Change in income during project period related to subsidy on Jersey cows

\begin{tabular}{ccc}
\hline Income Group (US\$ ${ }^{*}$ ) & Subsidy Received & Mean Value of Change in Income \\
\hline Less than 76.92 & No & -302.05 \\
$76.93-153.85$ & No & -437.31 \\
$153.86-384.62$ & No & 63.66 \\
$384.63-769.23$ & No & 3.4 .15 \\
& Yes & 420.51 \\
$769.24-1538.46$ & No & 578.06 \\
& Yes & 584.62 \\
\hline
\end{tabular}

Note: ${ }^{*} 1$ US\$ $=$ NU 65.

\subsection{Subsidy on Poultry}

Only $14.5 \%$ of the households received a subsidy on poultry products and those who received such a subsidy experienced 3 times higher increase in income compared to non-recipients (Table 3). It is quite evident such subsidies have been effective but its coverage is limited and consequently its benefits are not equitably shared. This is evidenced from the findings that only $14 \%$ of the poor against $17.6 \%$ of the rich received this subsidy. In absolute terms, the non-poor who received a subsidy experienced seven and half times greater gains in income (US\$2307.69) as compared to poor (US\$307.69) who also received a subsidy. The poor who received this subsidy experienced six times larger income gains as compared to those poor who did not. 
Table 3. Change in mean income from subsidy on poultry

\begin{tabular}{cc}
\hline Received Subsidy on Poultry & Mean Change in Income (US\$) \\
\hline No & 203.65 \\
Yes & 634.31 \\
Total & 265.69 \\
\hline
\end{tabular}

\subsection{Seeds and Saplings}

Subsidies for seeds showed a differential welfare effect for different income groups. OLS linear regression estimates indicated that a seed subsidy had a significant impact $(p<0.001)$ on income. For the lowest income group (less than US\$76.92), the income declined for both who received subsidy and who did not, but for those who received the seed subsidy experienced decline in annual income by three and half times more than those who did not receive such a subsidy (Table 4). In contrast to this, in the top two income groups, those who received subsidy experienced twice as much increase in income as those who did not. It requires a separate systematic study to examine the cause of such mixed results.

Table 4. Change in income during project period related to subsidy on seeds

\begin{tabular}{ccc}
\hline Income Group (US\$) & Received Subsidy & Mean Change in Income (US\$) \\
\hline \multirow{2}{*}{ Less than 76.92} & No & -147.86 \\
& Yes & -533.34 \\
$76.93-153.85$ & No & -580.51 \\
& Yes & -76.92 \\
\multirow{2}{*}{$153.86-384.62$} & No & 100.00 \\
& Yes & -4.95 \\
\multirow{2}{*}{$384.63-769.23$} & No & 221.43 \\
& Yes & 362.12 \\
$769.24-1538.46$ & No & 409.62 \\
& Yes & 759.49 \\
\hline
\end{tabular}

Ordinal logistical regression analysis indicates that those who receive a subsidy on seeds are likely to experience a $21 \%$ increase in income. Although a majority of the respondents believed that subsidies on saplings had positive effect on the income of the poor, this is not supported by regression estimates. This difference can be explained by the fact that such subsidy is given without any follow-up services on the proper use of saplings.

\subsection{Agricultural Machinery}

In the case of subsidies for agricultural machines, the bottom two income groups (less than 153.85) experienced 10 times higher decline in income than those who did not receive a subsidy. This subsidy was obviously counterproductive to the lower income group. For income groups higher than US $\$ 153.85$, this subsidy benefitted more to those who received subsidy.

\subsection{Effect of Proximity to Market on Income}

Distances from the nearest market also had a differential impact on the gains made by people who received subsidies. For all the subsidies, the major trend conveys that the places between 10-20 $\mathrm{km}$ from the nearest market place had yielded greater benefits to those who received various subsidies than for places located between $0-10$ and $>20 \mathrm{~km}$ from the nearest market places.

\section{Discussion}

Subsidies within the renewable natural resources sector are defined as either an additional government support in kind, in cash, or both, that are intended to provide meaningful benefit(s) to the 
farmers and other value chain intermediaries [21]. Subsidy components are concentrated to specified subsector interventions complementing regular development plans and programs of the renewable natural resource sector in Bhutan. Despite concerted efforts to assist poorer households and reduce inequalities by the Bhutanese government, findings showed that significant economic gains were reaped by mostly the non-poor households, thus beating the original objective of the subsidy program. However, Bhutan is not alone in grappling with such unintended outcome. Similar findings were reported by research world-wide [12,17,18,37]. For instance, Kau and Sharma, in their study on Indian agricultural subsidy, reported that agricultural subsidies are applied in ways that benefit mostly richer farmers, cause inefficiencies, lead to a fiscal burden, distort trade, and have negative environmental effects $[12,15,16]$. Such findings could also be attributed to affordability, as some subsidies require cost sharing by the farmers as in the case with Jersey cows in Bhutan.

In Bhutan's case, the co-payment requirement for acquiring some of the subsidies excluded those from lower income groups. For instance, the Jersey cow subsidy required a staggering co-payment of US\$276 (Nu.18,000) to US\$461 (Nu 30,000) for each cow. Farmers had an alternative to seek loans from financial institutions to cover the co-payment amount, but were challenged due to a lack of guarantees and mortgages. As result, Zhemgang district failed to distribute any of the 10 Jersey cows allocated for Bjoka which is one of the poorest blocks. When farmers were asked why they did not avail the subsidy, one representative responded, "we don't have enough money to meet basic needs and send our children to school, how we can pay such a huge amount for Jersey". However, those who did not avail this subsidy were at further disadvantage because this subsidy came with additional benefits such as free materials, including corrugated galvanized iron roof (CGI), cement, and sometimes bricks to construct Jersey sheds.

The availability of Jersey cows with the well-to-do households also set them in a more favorable position to avail the biogas subsidy (as Jersey cow ownership is a pre-requisite to accessing biogas), thereby benefiting them doubly. Biogas has many social and economic benefits to the rural households including savings from purchase and transportation of liquid petroleum gas cylinders (LPG), bio fertilizers, etc. However, in contradiction to the pro-poor goals, all the nine households who availed subsidy on biogas were non-poor who received a partial subsidy of about US $\$ 177(\mathrm{Nu} .11,500)$ to share the cost of biogas plant.

Findings clearly indicate that cost sharing requirement acts as an exclusionary device and prevents the poor from availing such a subsidy, especially when small holders are very poor. Furthermore, as indicated by the regression estimates, those who use biogas experienced more rapid growth in income (partially resulting from monetary savings from not having to purchase LPG, savings from transportation, and labor). This implies the cost sharing nature of such subsidy cannot be justified, as it prevents the poor from availing subsidies and helps non-poor farmers with faster income growth resulting in greater inequality. Subsidies, especially when they come with multiple benefits, must be targeted with enough incentives so that the poorest of the poor are not left behind. If implemented inclusively, such types of subsidy hold great potential to alleviate poverty, reduce income gaps, and also reduce import of cooking gas and other food items from India. A reduction in imports from India would reduce trade deficits between India and Bhutan as well as help save Bhutan's much exhausted foreign reserve.

Subsidized poultry on the other hand, benefitted the poor most, with significant economic benefits to the households. If scaled up, this subsidy can improve income for the poorer households and set them to avail bigger subsidies. However, increased growth of larger farms by the non-poor is an emerging competition that could wipe out small backyard poultry farms. This issue has already been raised in Eastern Bhutan where backyard poultry by small holders are losing out to larger semi-commercial farms [38].

While seed and sapling subsidies contributed positively to income generation, farmers and extension agents reported availability of land, irrigation, interest to grow, and manpower as some of the main constraints. Distribution of seeds and saplings to all the households irrespective of their 
interest to grow or availability of land has not only made it inefficient but also created secondary markets where they were sold and purchased.

The other hard reality is that farmers who have taken huge loans to purchase agricultural machinery with the expectation of improving income are not reaping as much benefit due to repayments. This demands a detailed cost-benefit analysis to guide our farmers effectively. Subsidies for piglets and fisheries reflected mixed trends but the overall impact on the income of those who received these subsidies has not been significantly different from those who did not receive subsidies.

It is obvious that places relatively close to markets have already realized larger potential benefits and farther places are too remote and have greater geographical disadvantage to make subsidies potentially gainful. It follows that there is a need to provide targeted and complete subsidy packages, including knowledge dissemination to the poor to ensure their fruitfulness and use.

\section{Conclusions}

Agricultural subsidies are an important strategy to improve farm income and alleviate income poverty. However, its application is also very complex given the socio-economic dimensions of the recipient households. Based on the study findings, we can conclude that the results of subsidies and the objectives of the agricultural subsidy program do not converge very well. The first objective of the draft subsidy policy is to ensure equitable access and promote more productive use of agricultural inputs. This objective is not fully realized, as lower income groups do not have equal access to all the subsidies, especially due to co-payment, availability of land, etc. On the contrary, higher income groups garnered most of these subsidies as well as the resultant gains in income. The second objective of the draft subsidy policy is to reduce vulnerability to food insecurity, which is also partially realized. People with higher income, larger land, and more education are less vulnerable to food insecurity as compared to those in the lower income group, who have less land and are less educated. The cost sharing requirement has acted as an exclusionary tool for the poor who were unable to avail some of the subsidies (especially, on Jersey cattle). If not checked, higher cost sharing could breed a danger of expanding indebtedness if the subsidies fail to contribute to rapid growth of income of its recipients. This might make people more vulnerable and would act against the overall objective of the subsidy policy. In summary, the current farm subsidy system is struggling to achieve its original goals and is in dire need of reform. If this aspect is not addressed, subsidies may only exacerbate inequality of income and asset distribution. We recommend that the current policy and programs on agricultural subsidies be reviewed and aligned with the overall support framework including better infrastructure, knowledge dissemination, capacity building, and provisioning of marketing support. Specifically, we describe the following policy suggestions:

- Target subsides to the areas 10-20 km from the market places so that benefits can be maximized. Alternatively, improve the condition of farm roads so that driving distances can be minimized.

- The government must base its subsidies on the area and productivity of land owned by individual households and their willingness and capacity to use subsidies.

- Subsidies like backyard poultry present efficient and effective opportunities for extremely poor households to start earning cash incomes to improve their ability to take advantage of bigger subsidies such as agricultural machinery or Jersey cows, etc.

- Free distribution of bricks and roofing materials for Jersey sheds must be withdrawn, because those availing such subsidies are better off already. Instead, savings from this withdrawal can be used to scale up smaller subsidies for lower income brackets.

- Local government capacity to assess subsidy needs and implementation abilities of individual households must be improved through appropriate training and awareness.

- Subsidies on agricultural machinery were obviously counterproductive for the lower income group and as such this subsidy may be either withdrawn or made 100\% subsidized for lower income groups. 
Author Contributions: The lead author S.W.W. was the principal investigator for the research and took the study from inception, through to field work, data management/analysis, and drafting the manuscript. W.-K.L. provided expert input into data interpretation and proofing the manuscript, while J.-G.K. provided technical inputs into cross referencing and interpretation. B.M. supported in producing the study area map interpreting results.

Funding: The research received no additional external funding.

Acknowledgments: The authors would like to thank the support from the agriculture officials and farmers who participated in the study; Ojeong Eco-Resilience Centre and RS/GIS Centre of Korea University for their technical and financial support in analysis and writing of this article.

Conflicts of Interest: The authors declare no conflict of interest.

\section{References}

1. WTO. The Doha Round; WTO: Geneva, Switzerland, 2001. Available online: https://www.wto.org/english/ tratop_e/dda_e/dda_e.htm (accessed on 12 January 2019).

2. Koo, W.; Kennedy, P.L. The impact of agricultural subsidies on global welfare. Am. J. Agric. Econ. 2006, 88, 1219-1226. [CrossRef]

3. Kirwan, B. The incidence of U.S. agricultural subsidies on farmland rental rates. J. Polit. Econ. 2009, 117, 138-164. [CrossRef]

4. Ricker-Gilbert, J.; Jayne, T.S. What are the enduring effects of fertilizer subsidy programs on recipient farm households? Evidence from Malawi. Res. Agric. Appl. Econ. 2011.

5. Harrigan, J. Food insecurity, poverty and the Malawian Starter Pack: Fresh start or false start? Food Policy 2008, 33, 237-249. [CrossRef]

6. Salunkhe, H.A.; Deshmush, B.B. The over view of Government subsidies in agriculture sector in India. J. Agric. Vet. Sci. 2012, 1, 43-47.

7. Henningsen, A.; Kumbhakar, S.; Lien, G. Econometric Analysis of the Effects of Subsidies on Farm Production in Case of Endogenous Input Quantities; Agricultural and Applied Economics Association: Milwaukee, WI, USA, 2009.

8. World Bank. Subsidies as an Instrument in Agricultural Finance: A Review; World Bank: Washington, DC, USA, 2008.

9. Cui, L.; Wu, K.J.; Tseng, M.L. Exploring a novel agricultural subsidy model with sustainable development: A Chinese agribusiness in Liaoning Province. Sustainability 2016, 9, 1. [CrossRef]

10. Fan, S.; Gulati, A.; Thorat, S. Investment, subsidies, and pro-poor growth in rural India. Agric. Econ. 2008, 39, 163-170. [CrossRef]

11. Nindi, T.C. Effects of the Farm Input Subsidy Program on Maize: Identifying Maize Supply and Demand Elasticities in Malawi; Mississippi State University: Starkville, MS, USA, 2015.

12. Kaur, R.; Sharma, M. Agricultural subsidies in India. Boon or curse. IOSR J. Humanit. Soc. Sci. 2012, 2, 40-46. [CrossRef]

13. Shively, G.E.; Ricker-Gilbert, J. Measuring the Impacts of Agricultural Input Subsidies in Sub-Saharan Africa: Evidence from Malawi's Farm Input Subsidy Program. Purdue Policy Res. Inst. (Ppri) Policy Briefs 2013, 1, 4.

14. Ricker-Gilbert, J.; Jayne, T.; Shively, G. Addressing the 'Wicked Problem' of Input Subsidy Programs in Africa: A Review; American Agricutural Economists Association: Seattle, WA, USA, 2012.

15. Liang, L.; Wang, Y.; Ridoutt, B.G.; Lal, R.; Wang, D.; Wu, W.; Wang, L.; Zhao, G. Agricultural subsidies assessment of cropping system from environmental and economic perspectives in North China based on LCA. Ecol. Indic. 2019, 96, 351-360. [CrossRef]

16. de Derecho Ambiental, C.M. The Economic and Environmental Impacts of Agricultural Subsidies: A Look at Mexico and Other OECD Countries; Unisféra International Centre: Unisféra, QC, Canada, 2003.

17. Clay, J. Are Agricultural Subsidies Causing More Harm than Good? The Guardian. 8 August 2013. Available online: https:/www.theguardian.com/sustainable-business/agricultural-subsidies-reform-governmentsupport (accessed on 11 November 2018).

18. Sharma, V. Impact of agricultural subsidies on National Income and agriculture production. Econ. Polit. Wkly. 1982, 47, 66-71. 
19. Statista. Bhutan: Share of Economic Sectors in the Gross Domestic Product (GDP) from 2007 to 2017. Available online: https://www.statista.com/statistics/527319/share-of-economic-sectors-in-the-gdp-inbhutan/ (accessed on 31 January 2019).

20. National Statistical Bureau. Statistical Year Book of Bhutan; Royal Government of Bhutan: Thimphu, Bhutan, 2010.

21. Moaf. Draft RNR Subsidy Policy; PPD Ministry of Agriculture and Forests: Thimphu, Bhutan, 2014.

22. Wond, T.; Macaulay, M. Evaluating local implementation: An evidence-based approach. Policy and Society 2010, 29, 161-169. [CrossRef]

23. Kumar, R. Research Methodology: A Step-by-Step Guide for Beginners; SAGE Publications: Saunders Oaks, CA, USA, 2005.

24. Holden, S.; Barrett, C.B.; Hagos, F. Food-for-work for poverty reduction and the promotion of sustainable land use: Can it work? Environ. Dev. Econ. 2006, 11, 15-38. [CrossRef]

25. Gulati, A.; Narayanan, S. The subsidy syndrome in Indian Agriculture; Oxford University Press: New Delhi, India, 2003.

26. Morgan, D.L. The Focus Group Guidebook; Sage Publications: Thousand Oaks, CA, USA, 1997; Volume 1.

27. Gabre-Madhin, E.Z.; Haggblade, S. Successes in African agriculture: Results of an expert survey. World Dev. 2004, 32, 745-766. [CrossRef]

28. Douben, N.; Ratnayake, R.M.W. Characteristic data on river floods and flooding; facts and figures. In Floods, from Defence to Management: Proceedings of the 3rd International Symposium on Flood Defence, Nijmegen, the Netherlands, 25-27 May 2005; Van Alphen, J., Van Beek, E., Taal, M., Eds.; CRC Press: Boca Raton, FL, USA, 2006; pp. 19-35.

29. Barriball, K.L.; While, A. Collecting data using a semi-structured interview. J. Adv. Nurs. Instit. Subscr. 1994, 19, 328-335. [CrossRef]

30. Hulme, D.; Shepherd, A. Conceptualizing chronic poverty. World Dev. 2003, 31, 403-423. [CrossRef]

31. Alkire, S.; Foster, J. Counting and multidimensional poverty measurement. J. Public Econ. 2011, 95, 476-487. [CrossRef]

32. Carter, M.R.; Travis, J.L. Consumption versus asset smoothing: Testing the implications of poverty trap theory in Burkina Faso. J. Dev. Econ. 2012, 99, 255-264. [CrossRef]

33. Gujarati, D.N. Basic Econometrics; McGraw Hill Book Co.: New York, NY, USA, 2003.

34. Hosmer, D.; Lemeshow, S. Applied Logistic Regression; John Wiley \& Sons: New York, NY, USA, 1989.

35. National Statistical Bureau. Bhutan Living Standards Survey (BLSS) 2014; Royal Government of Bhutan: Thimphu, Bhutan, 2014.

36. Filmer, D.; Pritchett, L.H. Estimating wealth effects without expenditure data-Or tears: An application to educational enrollments in states of India. Demography 2001, 38, 115-132.

37. Chibwana, C.; Fisher, M.; Shively, G. Cropland allocation effects of agricultural input subsidies in Malawi. World Dev. 2012, 40, 124-133. [CrossRef]

38. Kuensel. Helping Backyard Poultry Farms Bounce Back. 2015. Available online: http://www.kuenselonline. com/helping-backyard-poultry-farms-bounce-back/ (accessed on 11 March 2019).

(C) 2019 by the authors. Licensee MDPI, Basel, Switzerland. This article is an open access article distributed under the terms and conditions of the Creative Commons Attribution (CC BY) license (http://creativecommons.org/licenses/by/4.0/). 